\title{
Child characteristics and early intervention referral and receipt of services: a retrospective cohort study
}

Beth M. McManus ${ }^{1 *}$ D, Zachary Richardson ${ }^{1}$, Margaret Schenkman², Natalie J. Murphy², Rachel M. Everhart ${ }^{3}$, Simon Hambidge ${ }^{4}$ and Elaine Morrato ${ }^{1}$

\begin{abstract}
Background: Early Intervention (EI) is a federally mandated, state-administered system of care for children with developmental delays and disabilities under the age of three. Gaps exist in the process of accessing El through pediatric primary care, and low rates of El access are well documented and disproportionately affect poor and minority children. The aims of this paper are to examine child characteristics associated with gaps in El (1) referral, (2) access and (3) service use. To our knowledge, this is the first study to leverage linked safety net health system pediatric primary care and El records data to follow El-referred children longitudinally to understand El service use gaps from El referral to El service utilization.
\end{abstract}

Methods: In a retrospective cohort design ( 14,710 children with developmental disability or delay), we linked pediatric primary care records between a large, integrated safety net health system in metro Denver and its corresponding El program (2014-2016). Using adjusted marginal effects [ME, (95\% Cl)], we estimated gaps in El referral, access, and service type (i.e., physical [PT], occupational [OT], speech therapy [ST] and developmental intervention $[\mathrm{DI}]$ ). Analyses accounted for child characteristics including socio-demographics, diagnosis, condition severity, and baseline function.

Results: Only $18.7 \%$ of El-eligible children $(N=2726)$ received a referral; $26 \%$ of those $(N=722)$ received services for a net enrollment rate of 5\% among El-eligible children. Having the most severe developmental condition was positively associated with El referral $[\mathrm{ME}=0.334[0.249,0.420])$ and Individualized Family Services Plan (IFSP) receipt $[\mathrm{ME}=0.156[0.088,0.223])$. Children less likely to be El-referred were Black, non-Hispanic $(\mathrm{BNH})[\mathrm{ME}=-0.029(-0.054$, $-0.004)]$ and had a diagnosed condition ([ME $=-0.046(-0.087,-0.005)]$. Children with a diagnosis and those with higher income were more likely to receive PT or OT. Higher baseline cognitive and adaptive skills were associated with lower likelihood of PT [ME $=-0.029(-0.054,-0.004)]$, OT [ME $=-0.029(-0.054,-0.004)]$, and ST $[\mathrm{ME}=-0.029$ $(-0.054,-0.004)]$.

Conclusions: We identified and characterized gaps in El referral, access, and service use in an urban safety-net population of children with high rates of developmental delay. Interventions are needed to improve integrated systems of care affecting primary care and El processes and coordination.

Keywords: Early intervention, Developmental disabilities, Developmental delays, Safety net population, Health services research, Linked databases

\footnotetext{
* Correspondence: Beth.mcmanus@ucdenver.edu

1 Department of Health Systems, Management and Policy, Colorado School of

Public Health, 13001 E 17th Place, MS B119, Aurora, Colorado 80045, USA

Full list of author information is available at the end of the article
}

(c) The Author(s). 2020 Open Access This article is distributed under the terms of the Creative Commons Attribution 4.0 International License (http://creativecommons.org/licenses/by/4.0/), which permits unrestricted use, distribution, and reproduction in any medium, provided you give appropriate credit to the original author(s) and the source, provide a link to the Creative Commons license, and indicate if changes were made. The Creative Commons Public Domain Dedication waiver (http://creativecommons.org/publicdomain/zero/1.0/) applies to the data made available in this article, unless otherwise stated. 


\section{Background}

Part $\mathrm{C}$ of the Individuals with Disabilities Education Act authorizes states to establish statewide early intervention (EI) systems for infants and toddlers with developmental delays and diagnosed conditions [1]. Enrollment in EI is a multi-step process involving (1) screening and identification of eligible children, (2) referral of eligible children to EI services, (3) evaluation and determination of eligibility, and (4) access to EI services, which includes receipt of an EI care plan, as well as receiving billable services from an EI program. The core EI services consist of physical [PT], occupational [OT], speech [ST] therapy, and developmental intervention [DI]. Low rates of EI access have been well documented and disproportionately affect poor and minority children [2, 3]. The benefits of early developmental interventions have been described, [4, 5] but quantifying consequences of EI access gaps remains challenging. To mitigate EI access gaps, the American Academy of Pediatrics created an algorithm to improve identification and referral of EIeligible children [6]. Some systematic developmental screening initiatives have been partially successful and have improved EI referral rates, yet, in general, low EI referral rates persist [7-11]. There is evidence that referrals are missed due to simple oversight or communication failure between primary care, EI, and families as referral outcomes often are not formally tracked, and many EI-eligible children are not receiving EI services $[12,13]$. Since gaps in referral have been identified but are not yet well characterized, the first aim of this paper is to examine child characteristics associated with EI referral gaps.

Historically, research and interventions tend to focus on the primary care system and gaps between EI referral and receipt of EI eligibility evaluation, [8-11, 14] rather than following children longitudinally and focusing on long-term systems coordination. Achieving actual receipt of services entails joint responsibility of primary care, EI, and families. Pediatric providers guide and encourage EI engagement, EI programs facilitate care, while families must agree to treatment and engage in services. However, current models of primary care-EI coordination are apparently insufficient in tracking EI-referred patients $[15,16]$. Thus, Aim 2 is to examine child and family characteristics of EI-referred patients in relation to ultimately receiving an EI care plan, known as an Individualized Family Services Plan (IFSP), as a measure of receipt of services. We additionally follow the process one step further, as clinically determining need for EI-therapy is challenging and relying on diagnostic categories alone is insufficient [17]. Therefore, Aim 3 of this study is to examine child and family characteristics by EI service type(s) received as well as number of services received.
To our knowledge, this is the first study to leverage linked safety net health system pediatric primary care and EI records data to follow very low-income, predominantly minority EI-referred children longitudinally to understand EI service use gaps from EI referral to IFSP receipt to EI services receipt.

\section{Methods and declarations}

\section{Study design and population}

This was a retrospective cohort study linking primary care electronic health record data from Denver Health, a large, integrated safety net health system in Metro Denver, and administrative data from Rocky Mountain $\mathrm{Hu}$ man Services Early Intervention Program (RMHS) EI records. The cohort included children with developmental delay or disability who received at least one Denver Health well-child visit between 10/1/2014-6/30/2016. Denver Health includes a 477-bed hospital and 8 Federally Qualified health centers serving approximately 50,000 low-income children annually (35\% of Denver children). Their database includes children's clinical information, EI referral status, and sociodemographics. Previous research utilizing this database described service delivery gaps in pediatric obesity, [18] vaccines, [19] and developmental screening [20].

RMHS, located in Metro Denver, serves approximately 1000 families annually, including all Denver Healthreferred patients. The RMHS database includes service use and functional outcomes. All children referred to RMHS between 10/1/14-9/30/16 (i.e., a three-month lag from Denver Health data collection) were included, allowing us to include at least a 3-month time lag between EI referral and EI access to account for the federal mandate requiring an IFSP is written within 45 days of EI referral.

The cohort included children less than 35 months of age with a diagnosed condition or developmental delay (described in Explanatory variables). Children were linked via first and last names and dates of birth across the Denver Health and EI databases using the reclink2 algorithm in Stata [21]. Observations were kept as acceptable matches if the resultant probability of an exact match was $85 \%$ or greater [22].

\section{Ethics approval and consent to participate}

The Colorado Multiple Institutional Review Board approved this study and the Institutional Review Board at the Massachusetts Department of Public Health approved this study and the investigators' access to the data.

\section{El care variables}

The primary dependent variables were EI referral (Aim 1), IFSP receipt (Aim 2), and EI service type and number of services used (Aim 3). EI referral was ascertained from the 
Denver Health record. At Denver Health, EI referrals are entered by a provider, electronically documented, and sent directly to RMHS through a HIPAA-compliant portal. IFSP receipt was collected from the RMHS EI database. EI service type was assessed from the RMHS EI data based on receipt of any PT, OT, ST, or DI. Total number of EI services received from EI was categorized as 1, 2, and 3 or more. Of note, the vast majority of EI services occur in the child's home.

\section{Explanatory variables}

Covariates Ascertained from Denver Health. Child's race and ethnicity was categorized as white, non-Hispanic (WNH); black, non-Hispanic (BNH); Hispanic; and other race, non-Hispanic $(\mathrm{ONH}$; includes Asian, Pacific Islander and more than one race). Annual household income (less than $\$ 20,000$ or $\$ 20,000$ or more) reflects the Federal Poverty threshold for a family of three [23]. We included infant birthweight (less than $1500 \mathrm{~g}$, $1500-2500 \mathrm{~g}$, and greater than $2500 \mathrm{~g}$ ).

We also included measures of child's condition type and severity. Data was pulled from Denver Health based on children having the required ICD-9 codes for the study, which we then split into two condition types: diagnosed condition and developmental delay. ICD-9 codes corresponding to diagnoses in the EI-Colorado Established Condition Database indicated a diagnosed condition. Common diagnosed conditions included Down syndrome, autism, cerebral palsy, and extremely low birth weight [24]. Developmental delay was indicated by ICD-9 code 315 (generalized developmental delay) without a cooccurring diagnosed condition, which is typically attributed to children with a failed developmental screening. In Colorado, children are eligible for EI if they show a $25 \%$ delay in one or more developmental areas [25]. Of note, in 2012 Denver Health's information technology system underwent a major transformation allowing utilization of patient health records to provide tailored care, staff resources, and care-management services [26]. Simultaneously, electronic EI referrals for presumably EI-eligible children were implemented. Thus, ascertainment of condition type (i.e., diagnosis or delay) and EI referral are based upon validated processes.

Severity was categorized according to a clinically actionable 4-Tier severity algorithm employed by Denver Health based on published predictive models and frontline clinical judgement [26]. The four Tiers are comprised of (1) no chronic condition and age appropriate health service utilization; (2) mild condition requiring minimally elevated health service utilization; (3) moderate condition necessitating moderately elevated health service; and (4) severe chronic condition requiring high health service utilization. Due to clinical presentation heterogeneity, condition type and severity sub-groups do not overlap perfectly, however, the majority of Tier 1 and many Tier 2 children had a developmental delay only whereas the large majority of children in Tiers 3 and 4 had a diagnosed condition (such as cerebral palsy or Down syndrome).

Covariates Ascertained from RMHS. We included measures of child's sex (male/female), primary language spoken at home (English vs a language other than English), insurance type (private or public [includes Medicaid and Children's Health Insurance Program]) and age at EI entry (less than 12 months, 12-24 months, or 25-35 months). EI providers collect functional outcomes data at EI entry and exit for mandated reporting to the Office of Special Education Programs [27] in the form of Child Outcomes Summary (COS) scores. COS has been shown to have high clinical utility [28-30] and measures children's function in 1) Social-Emotional, 2) Acquiring and Using Knowledge and Skills (cognition), and 3) Adaptive/ Self-Care skills. Each domain score is a composite of parent and provider report and formal assessment comparing the child's function to that of typically developing peers on a 7 -point scale $[1=$ "very early skills" (i.e., child does not use any immediate foundational skills related to this outcome) to 7="all skills expected" (i.e., no concerns about the child's function)] [31]. More specifically, EI-CO developed age-anchored developmental tasks [32] to address each COS domain. Information to assess the acquisition of these developmental tasks can be ascertained from a combination of parent report, functional assessment results (e.g., EI-CO uses the Batelle Developmental Inventory-2 [BDI-2]), and provider clinical judgement. All CO-EI providers receive extensive training in the administration, scoring, an interpretation of BDI-2 and COS scores [33]. Yet, currently, RMHS does not have mechanisms in place to ensure routine COS collection, therefore there is not $100 \%$ compliance.

\section{Data analysis}

We first calculated descriptive statistics for each variable. To describe associations between child characteristics and EI care variables, we fit a series of adjusted logit regressions to estimate EI referral for Aim 1, and IFSP receipt and service type for Aims 2 and 3. Adjusted models included child's condition type, birthweight, age at EI entry, family income, race, ethnicity, sex, and baseline function. Analyses including baseline function were restricted to children with complete service use and COS information $(n=448)$.

To describe the association between child characteristics and the number of EI services received in Aim 3, we estimated adjusted ordinal logit regression models due to the ordered nature of service use categories. We estimated the marginal effects and 95\% CI of receiving each service use category (i.e., relative to the others) for each 
child characteristic. Marginal effects are interpreted as probabilities and estimate the associations between child characteristics and service use category. Compared to odds ratios, they are more intuitive and are not affected by extremely common or rare events [34, 35]. All analyses were conducted in Stata v14.2 [21].

\section{Results}

\section{Characteristics of study cohort}

The cohort included 14,710 children with either a developmental delay or a developmental disability. Of the 14,710 children, 2746 (18.7\%) were referred to EI and of those referred, 722 (26.3\%) received an IFSP (Fig. 1, Table 1). Of those with an IFSP, 571 initiated EI services, and of those, 448 had complete COS information (Fig. 1, Table 2). Children with and without complete COS information did not differ by clinical or sociodemographic characteristics (results not shown). Among children EI-referred and with an IFSP, $12.3 \%$ had a diagnosed condition, over $90 \%$ had an annual family income of less than $\$ 20,000,73.7 \%$ were Hispanic, $15 \%$ were white, non-Hispanic (WNH), and 13\% were black, non-Hispanic (BNH); 62.0\% were under 12 months of age, and $70.6 \%$ had no chronic condition $(n=1)$.

Mean (SD) entry COS scores were 3.7 (1.5) for Acquiring and Using Knowledge and Skills, 4.3 (1.7) for Adaptive/Self-Care, and 4.6 (1.8) for Positive Social Emotional function. Twenty-one percent of the EI sample received PT, $17.3 \%$ received OT, $74.4 \%$ received $\mathrm{ST}$, and $49.4 \%$ received DI (Table 2 ).

\section{Aim 1. Characteristics of El-referral gaps}

Children who had a diagnosis versus a developmental delay were $4.6 \%$ less likely $(\mathrm{ME}=-0.046[-0.087,-0.005)]$ to be EI-referred. Normal birthweight (> $2500 \mathrm{~g})$, and low birthweight (1501-2500 g) infants were 26.9\% (ME = $0.269[-0.365,-0.174)$ and $17.6 \%$ less likely $(\mathrm{ME}=-0.176$ $[-0.276,-0.077])$ than very low birthweight $(<1500 \mathrm{~g})$ infants to be referred. One-year olds were more likely to be EI-referred $[\mathrm{ME}=0.023[0.006,0.041])$ and 2-year olds were less likely to be EI-referred $[\mathrm{ME}=-0.042[-0.058$, $-0.025])$ than infants. BNH children were $2.9 \%$ less likely than WNH children $(\mathrm{ME}=-0.029[-0.054,-0.004])$ to be referred. Children with severe, moderate, and mild conditions were $33.4 \%(\mathrm{ME}=.334[0.249,0.420]), 33.8 \%(\mathrm{ME}=$ $0.338[0.314,0.461])$, and 9.8\% (ME = 0.098 [0.070, 0.127]), respectively, more likely than children with no special health care condition to be referred (Table 3).

\section{Aim 2. Characteristics of El access gaps}

Children with severe, moderate, and mild conditions were $15.6 \%(\mathrm{ME}=0.156[0.088,0.223]), 15.4 \% \quad(\mathrm{ME}=$ $0.154[0.095,0.213])$, and $2.4 \%(\mathrm{ME}=0.024, \quad[0.008$, $0.040]$ ), respectively, more likely than children with no special health care condition to receive an IFSP. Oneyear olds were more likely $[\mathrm{ME}=0.014[0.004,0.025]$ ) and two-year olds were less likely to receive an IFSP $[\mathrm{ME}=-0.031[-0.039,-0.023])$ than infants (Table 3 ).

\section{Aim 3. Characteristics of El service type gaps}

Children with diagnosed conditions were $22.5 \%$ more likely to receive PT $(\mathrm{ME}=0.225[0.104,0.347]), 21.4 \%$ more likely to receive OT $(\mathrm{ME}=0.214[0.091,0.337])$, and $22.4 \%$ more likely to receive $\mathrm{DI}(\mathrm{ME}=0.224[0.088,0.360])$ than children with a developmental delay (Table 4), and were also more likely to receive three or more services $(\mathrm{ME}=0.319$ $[0.199,0.440]$; Table 5). Low-income children were $13.6 \%$ less likely to receive PT $(\mathrm{ME}=-0.136[-0.201,-0.071])$ and $10.4 \%$ less likely to receive OT $(\mathrm{ME}=-0.104[-0.197$,

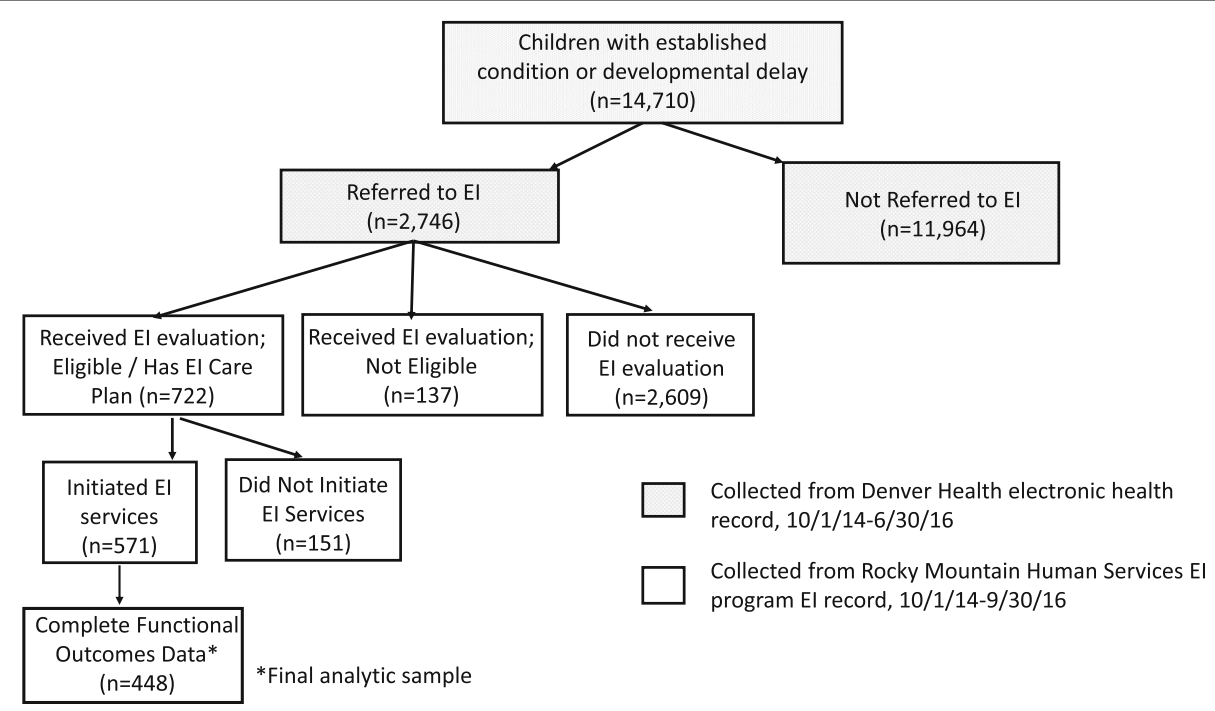

Fig. 1 Consort Diagram of Study Sample Selection 
Table 1 Characteristics of study sample children with developmental delays and disabilities $(n=14,710)$ within the study healthcare system

\begin{tabular}{lll}
\hline Not Referred & Referred, but \\
$(n=11,964)$ & $\begin{array}{l}\text { not Receiving El } \\
(n=2024)\end{array}$ & $\begin{array}{l}\text { Received and } \\
(n=722)\end{array}$ \\
\hline
\end{tabular}

Condition Type

Developmenta

Delay (DD)

Diagnosed 97.5

90.5

87.7

2.5

9.5

123

Condition Severity Group

$\begin{array}{lll}\text { No Condition } & 89.5 & 74.8 \\ \text { Mild } & 6.8 & 10.9 \\ \text { Moderate } & 2.0 & 9.0 \\ \text { Severe } & 1.6 & 5.4\end{array}$

Birthweight by Category

Less than $1.5 \mathrm{~kg} \quad 0.5$

$1.5 \mathrm{~kg}$ to $2.5 \mathrm{~kg} \quad 4.8$

Greater than $2.5 \mathrm{~kg} \quad 94.7$

74.8

70.6

10.9

$$
10.2
$$

9.0

5.4

11.0

8.2

Child's Age

Less than 12-Months
12-24 Months

Greater than 24

21.0

58.9

23.3

17.8

Months

Family Income (annually)

Less than $\$ 19,999 \quad 93.8$

Greater than $\$ 20,000 \quad 6.2$

Race/Ethnicity

White, non-Hispanic 15.0

Black, non-Hispanic $\quad 12.8$

Hispanic

$$
69.0
$$

Other, non-Hispanic $\quad 3.2$

Primary Language ${ }^{\mathrm{A}}$

$\begin{array}{ll}\text { English } & - \\ \text { Other } & -\end{array}$

Child's sex, Female

Insurance Type, Medicaid and $\mathrm{CHP}+{ }^{\mathrm{A}}$

${ }^{A}$ Characteristics only collected through El program, not pediatric primary care office

- 0.011]) than higher income children. Compared to children with birthweights less than $1500 \mathrm{~g}$, children in other birthweight groups were more likely to receive PT. Oneyear olds were $11.4 \%$ less likely $(\mathrm{ME}=-0.114[-0.213$, $0.016])$ and 2-year olds were $23.4 \%(\mathrm{ME}=-0.234[-0.400$, -0.086]) less likely to receive DI than infants (Table 4).

Children with higher baseline Social-Emotional function were $5 \%$ more likely to receive PT $(\mathrm{ME}=0.054[0.026$, $0.082])$ and $7.3 \%$ less likely to receive DI $(\mathrm{ME}=-0.073[-$
Table 2 Service Use among sample children who received El

\begin{tabular}{|c|c|}
\hline Characteristic & $\%(n)$ \\
\hline \multicolumn{2}{|l|}{ Type of El Services Received $(n=571)^{A}$} \\
\hline Physical Therapy & $21.4(122)$ \\
\hline Occupational Therapy & $17.3(99)$ \\
\hline Speech and Language Pathology & $74.4(425)$ \\
\hline Developmental Intervention & $49.4(282)$ \\
\hline \multicolumn{2}{|l|}{ Number of El Services Received $(n=571)$} \\
\hline One Service & $18.2(104)$ \\
\hline Two Services & $35.2(201)$ \\
\hline \multirow[t]{2}{*}{ Three or more Services } & $46.6(266)$ \\
\hline & Mean (SD) \\
\hline \multicolumn{2}{|c|}{ Child Outcome Survey (COS) score at El entry $(n=448)^{B}$} \\
\hline Positive Social Emotional Skills & $4.6(1.8)$ \\
\hline Acquiring and Using Knowledge and Skills & $3.7(1.5)$ \\
\hline Taking Appropriate Action to Meet Needs & $4.3(1.7)$ \\
\hline \multicolumn{2}{|c|}{$\begin{array}{l}\text { ADoes not add up to } 100 \% \text { since some children received more than one type } \\
\text { of El service; sub-sample of study children who initiated El services } \\
{ }^{B} \text { Each COS sub-scale score is derived from provider clinical judgment, parent } \\
\text { concerns, and developmental assessment results and measured on a } 7 \text {-point } \\
\text { scale, from } 1 \text { = very early skills (i.e., child does not use any immediate } \\
\text { foundational skills related to this outcome) to } 7 \text { = all skills expected (i.e., there } \\
\text { are no concerns about the child's function in this area) }\end{array}$} \\
\hline
\end{tabular}
referral and initiated El services

$0.112,-0.034]$. Children with higher baseline cognitive function were $3.9 \%$ more likely to receive $\mathrm{PT}(\mathrm{ME}=0.039$ $\left.\left[\begin{array}{ll}0.010 & 0.068\end{array}\right]\right)$ and $4.9 \%$ less likely to receive ST $(\mathrm{ME}=$ $0.049[-0.086,-0.011])$. Children with higher baseline Adaptive/Self-Care function were $5.1 \%$ less likely to receive OT $(\mathrm{ME}=-0.051[-0.078,-0.025]), 5.1 \%$ less likely to receive ST $(\mathrm{ME}=-0.051[-0.078,-0.025])$, and $5.8 \%$ more likely to receive DI $(\mathrm{ME}=0.058[0.027,0.090])$ (Table 4).

\section{Discussion}

Overall, we found significant gaps at each step of the EI referral-service delivery process. Among infants and toddlers with developmental delay or disability receiving care in a safety net health system, only $18.7 \%$ were EIreferred and only $26.3 \%$ of those EI-referred accessed EI (net access rate of less than 5\% of all eligible children). Moreover, service type and breadth was associated with child's income, diagnosis, and baseline function.

\section{El referral gaps}

A main finding of this study is that BNH children were less likely than their WNH counterparts to be EI-referred. While the reasons behind racial differences in EI referral are not explored in this study, these disparities in access have been reported [3]. A recent systematic review [36] of such research suggests that racial differences in care stem, in part, from differences in provider behavior. Providers tend to dismiss parental developmental concerns and abnormal 
Table 3 Adjusted marginal effects [95\% Cl] of El Referred Only $(n=2024)$ and Referred and Received IFSP $(n=722)$ sub-groups for each child characteristic

\begin{tabular}{lll}
\hline Independent Variables & Referred Only & $\begin{array}{l}\text { Referred and } \\
\text { Received IFSP }\end{array}$ \\
\hline Diagnosed Condition $^{\mathrm{A}}$ & $-0.046^{*}$ & -0.015 \\
& {$[-0.087,-0.005]$} & {$[-0.030,0.001]$}
\end{tabular}

Condition Severity Group

$\begin{array}{lll}\text { No Condition } & \text { ref } & \text { ref } \\ \text { Mild } & 0.098^{* * *} & 0.024^{* *} \\ & {[0.070,0.127]} & {[0.008,0.040]} \\ \text { Moderate } & 0.388^{* * *} & 0.154^{* * *} \\ & {[0.314,0.461]} & {[0.095,0.213]} \\ \text { Severe } & 0.334^{* * *} & 0.156^{* * *} \\ & {[0.249,0.420]} & {[0.088,0.223]}\end{array}$

Birthweight by Category

Less than $1.5 \mathrm{~kg}$

$1.5 \mathrm{~kg}$ to $2.5 \mathrm{~kg}$

Greater than $2.5 \mathrm{~kg}$

Child's Age

Less than 12-Months

12-24 Months

Greater than 24-Months

ref ref

$-0.176^{* * *} \quad-0.000$

$[-0.276,-0.077]$

$[-0.036,0.036]$

$-0.269^{* * *}-0.021$

$[-0.365,-0.174] \quad[-0.054,0.012]$

Family Income (annually)

Greater than $\$ 20,000$

ref ref

$0.023^{* *}$

$0.014^{* *}$

$[0.006,0.041] \quad[0.004,0.025]$

$-0.042^{* * *}-0.031^{* * *}$

$[-0.058,-0.025]$

$[-0.039,-0.023]$

$$
\begin{aligned}
& -0.009 \\
& {[-0.034,0.017]}
\end{aligned}
$$

0.011

$[-0.004,0.027]$

Race/Ethnicity

\begin{tabular}{lll} 
White, non-Hispanic & ref & ref \\
Black, non-Hispanic & $-0.029^{*}$ & -0.012 \\
& {$[-0.054,-0.004]$} & {$[-0.025,0.002]$} \\
Hispanic & 0.017 & 0.006 \\
& {$[-0.002,0.037]$} & {$[-0.005,0.017]$} \\
Other, non-Hispanic & 0.019 & -0.015 \\
& {$[-0.024,0.061]$} & {$[-0.035,0.004]$} \\
Child's sex, Female & $-0.078^{* * *}$ & $-0.020^{* * *}$ \\
& {$[-0.091,-0.065]$} & {$[-0.027,-0.012]$} \\
\hline
\end{tabular}

${ }^{A}$ Diagnosed conditions for El eligibility can be found in the Colorado Established Condition Database ${ }^{20}$, the referent group is children with developmental delay only ${ }^{*} p<.05 ;{ }^{* *} p<.01 ;{ }^{* * *} p<.001$

developmental screening results and attribute them to social rather than clinical risk for $\mathrm{BNH}$ families compared to WNH, which could translate to fewer EI referrals.

The second main finding of this paper is that children with diagnosed conditions were less likely than their peers with a developmental delay to be EI-referred after accounting for condition severity. It may be that children with diagnosed conditions are being referred to specialty clinics more often and receiving care outside of EI [37]. In fact, one study found that half of birth to 3 year olds with a developmental condition receive clinic-based therapy services [38]. Additionally, children with more severe conditions are more likely to receive an EI referral regardless of their condition type. These findings highlight the clinical complexity of EI-eligible children and suggest that children most likely to receive an EI referral are those whose condition aligns with federal and CO-EI eligibility (e.g., developmental delay, extremely low birth weight, and high need special healthcare conditions).

\section{El access gaps}

The third main finding of this paper is that, compared to infants, 2-year olds are less likely to receive an IFSP. While this study cannot examine causality and there are limited comparable findings, it suggests caregivers of 2year olds with developmental concerns need tailored support to navigate the EI system, especially since they typically interface less with primary care and have a shorter time window to access EI.

While we have limited comparisons for EI access findings, one study found that $30-50 \%$ of EI-referred children receiving care in urban pediatric practices received an EI evaluation, [11] fitting with $31 \%$ in our sample (Fig. 1). Moreover, we found that children with greater condition severity were more likely to access EI and that the majority of our cohort had a developmental delay (versus established condition), also consistent with previous literature $[5,36]$.

Reasons for access gaps may be numerous, and have been explored in previous studies $[15,16]$. Future research should engage EI stakeholders (pediatricians, EI providers and parents) to understand EI enrollment barriers as previous research suggests that increasing family engagement [15] and implementing cross-system strategies such as centralized referrals and patient navigators can bolster EI enrollment [16].

\section{El service type gaps}

We found EI service use gaps among the poorest cohort children. In this safety net population, higher income may be a marker for greater economic resources, knowledge, or capacity to advocate for PT and OT and future research should explore EI therapy barriers and facilitators.

We also found that having a diagnosed condition (versus developmental delay) was associated with higher likelihood of receiving a greater breadth of EI services. While having a diagnosis seems to trigger an EI referral less often, once these children access EI they receive a greater breadth of services than their peers with developmental delays. Future research should focus on therapy 
Table 4 Adjusted marginal effects [95\% Cl] of receiving a core El service among sample children with complete outcomes information $^{\text {A }}$

\begin{tabular}{|c|c|c|c|c|}
\hline Independent Variables & $\begin{array}{l}\text { Marginal Effects } \\
\text { of any PT }\end{array}$ & $\begin{array}{l}\text { Marginal Effects } \\
\text { of any OT }\end{array}$ & $\begin{array}{l}\text { Marginal Effects } \\
\text { of any ST }\end{array}$ & $\begin{array}{l}\text { Marginal Effects } \\
\text { of any DI }\end{array}$ \\
\hline \multirow[t]{2}{*}{ Had a Diagnosis } & $0.225^{* * *}$ & $0.214^{* * *}$ & 0.084 & $0.224^{* *}$ \\
\hline & {$[0.104,0.347]$} & {$[0.091,0.337]$} & {$[-0.030,0.197]$} & {$[0.088,0.360]$} \\
\hline \multicolumn{5}{|l|}{ Birthweight by Category } \\
\hline Less than $1.5 \mathrm{~kg}$ & ref & ref & ref & ref \\
\hline \multirow[t]{2}{*}{$1.5 \mathrm{~kg}$ to $2.5 \mathrm{~kg}$} & $0.177^{*}$ & -0.056 & -0.210 & -0.010 \\
\hline & {$[0.026,0.328]$} & {$[-0.260,0.148]$} & {$[-0.463,0.044]$} & {$[-0.331,0.311]$} \\
\hline \multirow[t]{2}{*}{ Greater than $2.5 \mathrm{~kg}$} & $0.135^{* *}$ & -0.014 & -0.102 & -0.121 \\
\hline & {$[0.041,0.228]$} & {$[-0.194,0.167]$} & {$[-0.318,0.115]$} & {$[-0.406,0.164]$} \\
\hline \multicolumn{5}{|l|}{ Child's Age } \\
\hline Less than 12-Months & ref & ref & ref & ref \\
\hline \multirow[t]{2}{*}{ 12-24 Months } & -0.024 & -0.037 & -0.080 & $-0.114^{*}$ \\
\hline & {$[-0.096,0.048]$} & {$[-0.111,0.036]$} & {$[-0.179,0.018]$} & {$[-0.213,-0.016]$} \\
\hline \multirow[t]{2}{*}{ Greater than 24-Months } & 0.013 & 0.045 & 0.034 & $-0.234^{* *}$ \\
\hline & {$[-0.112,0.138]$} & {$[-0.103,0.192]$} & {$[-0.103,0.170]$} & {$[-0.400,-0.068]$} \\
\hline \multicolumn{5}{|l|}{ Family Income (annually) } \\
\hline \multirow[t]{2}{*}{ Greater than $\$ 20,000$} & $-0.136^{* * *}$ & $-0.104^{*}$ & -0.078 & 0.057 \\
\hline & {$[-0.201,-0.071]$} & {$[-0.197,-0.011]$} & {$[-0.230,0.075]$} & {$[-0.092,0.207]$} \\
\hline \multicolumn{5}{|l|}{ Race/Ethnicity } \\
\hline White, non-Hispanic & ref & ref & ref & ref \\
\hline \multirow[t]{2}{*}{ Black, non-Hispanic } & 0.034 & -0.003 & 0.045 & 0.041 \\
\hline & {$[-0.125,0.193]$} & {$[-0.157,0.152]$} & {$[-0.142,0.232]$} & {$[-0.156,0.239]$} \\
\hline \multirow[t]{2}{*}{ Hispanic } & 0.001 & -0.037 & -0.004 & -0.097 \\
\hline & {$[-0.097,0.099]$} & {$[-0.144,0.071]$} & {$[-0.126,0.118]$} & {$[-0.243,0.048]$} \\
\hline \multirow[t]{2}{*}{ Other, non-Hispanic } & 0.056 & -0.093 & -0.036 & -0.047 \\
\hline & {$[-0.141,0.253]$} & {$[-0.357,0.172]$} & {$[-0.339,0.267]$} & {$[-0.332,0.238]$} \\
\hline \multirow[t]{2}{*}{ Child's sex, Female } & 0.028 & -0.054 & -0.026 & -0.006 \\
\hline & {$[-0.040,0.096]$} & {$[-0.121,0.014]$} & {$[-0.112,0.060]$} & {$[-0.100,0.087]$} \\
\hline \multirow[t]{2}{*}{ Primary Language, English } & 0.013 & 0.017 & -0.028 & 0.049 \\
\hline & {$[-0.062,0.088]$} & {$[-0.062,0.097]$} & {$[-0.121,0.064]$} & {$[-0.053,0.151]$} \\
\hline \multirow[t]{2}{*}{ Insurance Type, Medicaid and CHP+ } & -0.067 & 0.007 & 0.039 & $0.157^{*}$ \\
\hline & {$[-0.186,0.053]$} & {$[-0.109,0.122]$} & {$[-0.111,0.188]$} & {$[0.005,0.309]$} \\
\hline \multicolumn{5}{|l|}{ Entry Child Outcome Summary Sub-Scales ${ }^{B}$} \\
\hline \multirow[t]{2}{*}{ Positive Social Emotional Skills } & $0.054^{* * *}$ & -0.002 & -0.017 & $-0.073^{* * *}$ \\
\hline & {$[0.026,0.082]$} & {$[-0.032,0.028]$} & {$[-0.055,0.020]$} & {$[-0.112,-0.034]$} \\
\hline \multirow[t]{2}{*}{ Acquiring and Using Knowledge and Skills } & $0.039^{* *}$ & 0.009 & $-0.049^{*}$ & 0.032 \\
\hline & {$[0.010,0.068]$} & {$[-0.021,0.039]$} & {$[-0.086,-0.011]$} & {$[-0.009,0.072]$} \\
\hline \multirow[t]{2}{*}{ Taking Appropriate Action to Meet Needs } & $-0.095^{* * *}$ & $-0.051^{* * *}$ & $0.058^{* * *}$ & 0.033 \\
\hline & {$[-0.125,-0.066]$} & {$[-0.078,-0.025]$} & {$[0.027,0.090]$} & {$[-0.003,0.068]$} \\
\hline
\end{tabular}

${ }^{\mathrm{A}}$ Sample includes 448 children with complete baseline Child Outcomes Summary Data

${ }^{*} p<.05 ;{ }^{* *} p<.01 ;{ }^{* * *} p<.001$

${ }^{B}$ Each COS sub-scale score is derived from provider clinical judgment, parent concerns, and developmental assessment results and measured on a 7-point scale, from $1=$ very early skills (i.e., child does not use any immediate foundational skills related to this outcome) to $7=$ all skills expected (i.e., there are no concerns about the child's function in this area) 
Table 5 Adjusted marginal effects [95\% Cl] of the number of El services among sample children who initiated El services and have complete child outcomes information ${ }^{\mathrm{A}}$

\begin{tabular}{|c|c|c|c|}
\hline \multirow[b]{2}{*}{ Independent Variables } & \multicolumn{3}{|c|}{ Marginal Effects of Number of Services (Compared to other Service Groups) } \\
\hline & One Service & Two Services & Three or More Services \\
\hline \multirow[t]{2}{*}{ Had a Diagnosis } & $-0.143^{* * *}$ & $-0.176^{* * *}$ & $0.319^{* * *}$ \\
\hline & {$[-0.194,-0.092]$} & {$[-0.257,-0.095]$} & {$[0.199,0.440]$} \\
\hline \multicolumn{4}{|l|}{ Birthweight by Category } \\
\hline Less than $1.5 \mathrm{~kg}$ & ref & ref & ref \\
\hline \multirow[t]{2}{*}{$1.5 \mathrm{~kg}$ to $2.5 \mathrm{~kg}$} & -0.025 & -0.018 & 0.043 \\
\hline & {$[-0.201,0.151]$} & {$[-0.132,0.096]$} & {$[-0.247,0.332]$} \\
\hline \multirow[t]{2}{*}{ Greater than $2.5 \mathrm{~kg}$} & 0.001 & 0.000 & -0.001 \\
\hline & {$[-0.161,0.162]$} & {$[-0.099,0.099]$} & {$[-0.262,0.260]$} \\
\hline \multicolumn{4}{|l|}{ Child's Age } \\
\hline Less than 12-Months & ref & ref & ref \\
\hline \multirow[t]{2}{*}{ 12-24 Months } & $0.078^{*}$ & $0.044^{*}$ & $-0.122^{*}$ \\
\hline & {$[0.006,0.151]$} & {$[0.009,0.078]$} & {$[-0.226,-0.019]$} \\
\hline \multirow[t]{2}{*}{ Greater than 24-Months } & 0.073 & 0.042 & -0.114 \\
\hline & {$[-0.052,0.197]$} & {$[-0.010,0.093]$} & {$[-0.288,0.060]$} \\
\hline \multicolumn{4}{|l|}{ Family Income (annually) } \\
\hline \multirow[t]{2}{*}{ Greater than $\$ 20,000$} & -0.054 & -0.044 & 0.098 \\
\hline & {$[-0.134,0.025]$} & {$[-0.124,0.036]$} & {$[-0.060,0.257]$} \\
\hline \multicolumn{4}{|l|}{ Race/Ethnicity } \\
\hline White, non-Hispanic & ref & ref & ref \\
\hline \multirow[t]{2}{*}{ Black, non-Hispanic } & -0.021 & -0.024 & 0.045 \\
\hline & {$[-0.111,0.069]$} & {$[-0.127,0.079]$} & {$[-0.148,0.238]$} \\
\hline \multirow[t]{2}{*}{ Hispanic } & 0.061 & 0.046 & -0.107 \\
\hline & {$[-0.015,0.137]$} & {$[-0.022,0.114]$} & {$[-0.249,0.035]$} \\
\hline \multirow[t]{2}{*}{ Other, non-Hispanic } & 0.084 & 0.056 & -0.140 \\
\hline & {$[-0.037,0.205]$} & {$[-0.019,0.132]$} & {$[-0.331,0.051]$} \\
\hline \multirow[t]{2}{*}{ Child's sex, Female } & -0.003 & -0.002 & 0.005 \\
\hline & {$[-0.061,0.054]$} & {$[-0.039,0.034]$} & {$[-0.089,0.100]$} \\
\hline \multirow[t]{2}{*}{ Primary Language, English } & -0.016 & -0.010 & 0.026 \\
\hline & {$[-0.079,0.047]$} & {$[-0.049,0.029]$} & {$[-0.075,0.128]$} \\
\hline \multirow[t]{2}{*}{ Insurance Type, Medicaid and CHP+ } & -0.040 & -0.021 & 0.061 \\
\hline & {$[-0.166,0.086]$} & {$[-0.074,0.032]$} & {$[-0.118,0.239]$} \\
\hline \multicolumn{4}{|l|}{ Child Outcomes Summary Sub-Scales ${ }^{B}$} \\
\hline \multirow[t]{2}{*}{ Positive Social Emotional Skills } & $0.027^{*}$ & $0.017^{*}$ & $-0.044^{*}$ \\
\hline & {$[0.002,0.053]$} & {$[0.001,0.033]$} & {$[-0.084,-0.004]$} \\
\hline \multirow[t]{2}{*}{ Acquiring and Using Knowledge and Skills } & -0.008 & -0.005 & 0.013 \\
\hline & {$[-0.032,0.016]$} & {$[-0.020,0.010]$} & {$[-0.026,0.052]$} \\
\hline \multirow[t]{2}{*}{ Taking Appropriate Action to Meet Needs } & -0.007 & -0.004 & 0.012 \\
\hline & {$[-0.029,0.014]$} & {$[-0.018,0.009]$} & {$[-0.023,0.047]$} \\
\hline
\end{tabular}

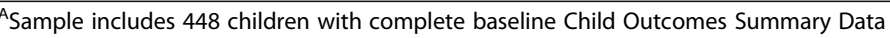

${ }^{*} p<.05 ;{ }^{* *} p<.01 ;{ }^{* * *} p<.001$

${ }^{\mathrm{B}}$ Each COS sub-scale score is derived from provider clinical judgment, parent concerns, and developmental assessment results and measured on a 7-point scale, from $1=$ very early skills (i.e., child does not use any immediate foundational skills related to this outcome) to $7=$ all skills expected (i.e., there are no concerns about the child's function in this area) 
use among EI-enrolled children as previous literature is mixed with regard to service type disparities [39].

This study also examined the association between routinely collected global measures of children's function and EI service use. Baseline functional skills were associated with core EI service use in expected directions, suggesting baseline COS scores may be a good marker of EI therapy need. For example, children with higher socialemotional function likely have less need for DI, which focuses, in part, on promoting social skills.

\section{Limitations}

The data were ascertained from one health system and EI program. However, Denver Health serves as medical home to 50,000 low-income children in Metro Denver and RMHS serves approximately $2 / 3$ of Metropolitan Denver EI-eligible children. Thus, although results may not be generalizable to the general EI-population, they are applicable to lower-income, urban, EI-eligible children; and in fact, nearly $50 \%$ of EI-enrolled children nationally are low-income [5]. Related, the prevalence rate of children with developmental conditions in this sample $(14,710 / 50,000=29.4 \%)$ is comparable to national estimates of low-income infants and toddlers with or at risk for developmental delays [40]. We were unable to examine reasons for EI referral (i.e., beyond a diagnosis), EI care quality, parental concerns, or capacity to navigate or advocate within the EI system. Previous research suggests that low EI enrollment rates can be explained, in part, by families who refuse services or do not follow up on EI referrals, [15] and families play an integral role in accessing EI services. Finally, we assume that children who received diagnostic code consistent with EI-eligible conditions in $\mathrm{CO}$ are, in fact, EI-eligible. However, we have no way to confirm this among the children who did not receive an EI evaluation. Yet, if pediatricians document a developmental delay in a child's medical record, it seems plausible that developmental follow-up or referral is warranted. Additionally, Colorado eligibility for EI stipulates that a child has a $25 \%$ or greater delay in one or more developmental areas [25], and in this study we found that very few children who received an EI evaluation were found ineligible (Fig. 1). Future research should conduct qualitative interviews with providers and parents to understand care quality, including shared decision-making, and EI service gaps.

\section{Strengths}

To our knowledge, this is the first study to link pediatric primary care and EI records to examine EI service use among a low-income EI-eligible cohort. We found differences in receipt of EI therapy services by condition type, income, and baseline function. These findings have important implications for EI providers, program directors, and policy makers for improving outreach and care planning. The methods of this study can serve as a model for leveraging electronic health data to examine EI service use gaps with an eye toward improving access, service use patterns, and functional outcomes.

Our findings of the prevalence of developmental delays is well aligned with national estimates of the prevalence of children at risk for developmental delay in lowincome settings [40]. We also found that most children receiving EI services are doing so because of a developmental delay, rather than a diagnosed condition, which also matches previous findings [41] and bolsters the validity of our results. Moreover, our EI-referral rate of $18.7 \%$ is consistent with previous literature examining developmental follow-up for urban children with a failed developmental screening, [10] suggesting generalizability to similar populations.

\section{Conclusion and clinical implications}

Our findings highlight the multiple decision-makers in the EI enrollment loop: pediatricians make an EI referral, EI providers recommend EI service type, and families make the final decisions regarding receipt of services. To minimize EI access gaps and ensure that all eligible children are referred to and receive EI services, our findings suggest opportunities for improved family engagement, in addition to communication and coordination between pediatric primary care and EI systems at each step of the EI enrollment process.

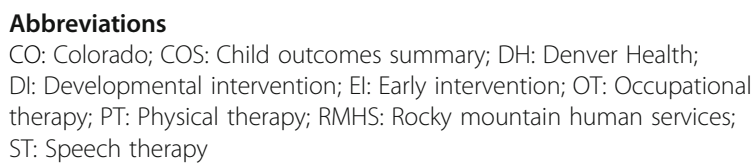

\section{Acknowledgements}

Not applicable.

\section{Authors' contributions}

BM conceptualized and designed the study, drafted the initial manuscript, supervised data collection and analysis and revised the manuscript critically for important intellectual content. RE, ZR designed the data collection instruments, collected data, and revised the manuscript critically for important intellectual content. ZR and NM contributed to the conception and design of the study and conducted analyses and data interpretation, and revised the manuscript critically for important intellectual content. EM, MS, and SH contributed to the conception and design of the study, supervised data analysis interpretation and critically reviewed the manuscript for important intellectual content. All authors read and approved the final manuscript.

\section{Funding}

Dr. McManus acknowledges funding from the Comprehensive Opportunities in Rehabilitation Research Training (K12 HD055931). The funding body had no role in the design of the study and collection, analysis, and interpretation of data or in writing the manuscript.

\section{Availability of data and materials}

The datasets generated and analyzed during the current study are not publicly available because they contain personal health information, but are available from the corresponding author on reasonable request. 


\section{Ethics approval and consent to participate}

This study was approved by the Colorado Multiple Institutional Review Board. As secondary data was used, no consent to participate was required.

\section{Consent for publication}

Not applicable.

\section{Competing interests}

The authors declare that they have no competing interests.

\section{Author details}

'Department of Health Systems, Management and Policy, Colorado School of Public Health, 13001 E 17th Place, MS B119, Aurora, Colorado 80045, USA. ${ }^{2}$ Physical Therapy Program, University of Colorado School of Medicine, 13121 East 17th Ave. Mail Stop C244, Aurora, Colorado 80045, USA. ${ }^{3}$ Ambulatory Care Services Data and Analytics Denver Health, 777 Bannock St., Denver, Colorado 80204, USA. ${ }^{4}$ Denver Community Health Services, 777 Bannock St. Denver, Colorado 80204, USA.

Received: 23 May 2019 Accepted: 7 February 2020

Published online: 22 February 2020

\section{References}

1. Individuals with Disabilities Education Act, Reauthorization. In: Public Law 108-446. 2004

2. Twardzik E, Cotto-Negron C, MacDonald M. Factors related to early intervention part C enrollment: a systematic review. Disabil Health J. 2017;10(4):467-74.

3. Feinberg $E$, Silverstein $M$, Donahue $S$, Bliss R. The impact of race on participation in part C early intervention services. J Dev Behav Pediatr. 2011;32(4):284-91.

4. Spittle A, Treyvaud K. The role of early developmental intervention to influence neurobehavioral outcomes of children born preterm. Semin Perinatol. 2016;40(8):542-8.

5. Hebbeler K, Spiker D, Bailey D, Scarborough A, Mallik S, Simeonsson R, Singer $M$, Nelson L: Final report of the national early intervention longitudinal study (NEILS). 2007. Accessed 1 Nov 2016.

6. Disabilities CoCW, Pediatrics SoDB, Committee BFS, Committee MHIfCWSNPA: Identifying infants and young children with developmental disorders in the medical home: an algorithm for developmental surveillance and screening. Pediatrics 2006, 118(1):405.

7. Talmi A, Bunik M, Asherin R, Rannie M, Watlington T, Beaty B, Berman S. Improving developmental screening documentation and referral completion. Pediatrics. 2014;134(4):e1181-8.

8. King TM, Tandon SD, Macias MM, Healy JA, Duncan PM, Swigonski NL, Skipper SM, Lipkin PH. Implementing developmental screening and referrals: lessons learned from a national project. Pediatrics. 2010;125(2):350-60.

9. Earls MF, Andrews JE, Hay SS. A longitudinal study of developmental and behavioral screening and referral in North Carolina's assuring better child health and development participating practices. Clin Pediatr (Phila). 2009:48(8):824-33.

10. Marks KP, Page Glascoe F, Macias MM. Enhancing the algorithm for developmental-behavioral surveillance and screening in children 0 to 5 years. Clin Pediatr (Phila). 2011;50(9):853-68.

11. Guevara J, Gerdes M, Localio R, Huang Y. Effectiveness of developmental screening in an urban setting. Pediatrics. 2013;131:30-37.

12. Little AA, Kamholz K, Corwin BK, Barrero-Castillero A, Wang CJ. Understanding barriers to early intervention Services for Preterm Infants: lessons from two states. Acad Pediatr. 2015;15(4):430-8.

13. Rosenberg SA, Zhang D, Robinson CC. Prevalence of developmental delays and participation in early intervention services for young children. Pediatrics. 2008:121(6):e1503-9.

14. Jimenez ME, Fiks AG, Shah LR, Gerdes M, Ni AY, Pati S, Guevara JP. Factors associated with early intervention referral and evaluation: a mixed methods analysis. Acad Pediatr. 2014;14(3):315-23.

15. Conroy K, Rea C, Kovacikova G, Sprecher E. Ensuring Timely Connection to Early Intervention for Young Children With Developmental Delays. Pediatrics. 2018;142(1):e20174017.

16. Moore C, Zamora I, Patel Gera M, Williams ME. Developmental screening and referrals: assessing the influence of provider specialty, training, and interagency communication. Clin Pediatr (Phila). 2017:56(11):1040-7.

17. McManus BM, Rapport MJ, Richardson Z, Lindrooth R. Therapy use for children with developmental conditions: analysis of Colorado Medicaid data. Pediatr Phys Ther. 2017;29(3):192-8.
18. Davidson AJ, McCormick EV, Dickinson LM, Haemer MA, Knierim SD, Hambidge SJ. Population-level obesity surveillance: monitoring childhood body mass index z-score in a safety-net system. Acad Pediatr. 2014;14(6):632-8.

19. Farmar A-LM, Love-Osborne K, Chichester K, Breslin K, Bronkan K, Hambidge SJ. Achieving high adolescent HPV vaccination coverage. Pediatrics. 2016; 138(5):e20152653.

20. Rodrigues KK, Hambidge SJ, Dickinson M, Richardson DB, Davidson AJ. Developmental screening disparities for languages other than English and Spanish. Acad Pediatr. 2016;16(7):653-9.

21. StataCorp: Stata Statistical Software: Release 15. College Station. TX: StataCorp LLC: 2017.

22. Sauleau EA, Paumier J-P, Buemi A. Medical record linkage in health information systems by approximate string matching and clustering. BMC Med Inform Decis Mak. 2005;5:32.

23. U.S. Federal Poverty Guidelines Used to Determine Financial Eligibility for Certain Federal Programs [https://aspe.hhs.gov/poverty-guidelines]. Accessed 15 July 2017.

24. Established Condition Database - Early Intervention Colorado. [https://docs. google.com/spreadsheets/d/14ZfUsdLaMiv4ULd9oP-xkUVaPkKQQ7KI_ yhrPOiFwqA/edit-gid=0]. Accessed 12 Nov 2018.

25. Social Services Rules: Early Intervention Program. In: 12 CCR 2509-10. Edited by Services DoH. Colorado: Secretary of State: 4 .

26. Johnson TL, Brewer D, Estacio R, Vlasimsky T, Durfee MJ, Thompson KR, Everhart RM, Rinehart DJ, Batal H: Augmenting predictive modeling tools with clinical insights for care coordination program design and implementation. eGEMs 2015, 3(1).

27. Outcomes Measurement: Federal Requirements [http://ectacenter.org/eco/ pages/fed_req.asp]. Accessed 20 Apr 2018.

28. Richardson ZS, Scully EA, Dooling-Litfin JK, Murphy NJ, Rigau B, Khetani MA, McManus BM. Early intervention service intensity and change in children's functional capabilities. Arch Phys Med Rehabil. 2019. https://doi.org/10.1016/ j.apmr.2019.10.188

29. Noyes-Grosser DM, Elbaum B, Wu Y, Siegenthaler KM, Cavalari RS, Gillis JM, Romanczyk RG. Early intervention outcomes for toddlers with autism spectrum disorder and their families. Infants Young Child. 2018:31(3):177-99.

30. Barton L, Spiker D, Hebbeler K, Taylor C, Williamson C. ENHANCE Final Report. SRI International. 2015:9-14.

31. Child Outcomes Measurement and Materials Information [http://www eicolorado.org/index.cfm?fuseaction=Professionals.content\&linkid=712 ].

32. State-Developed COS Materials [https:/ectacenter.org/eco/pages/cosstates.asp]. Accessed 3 Nov 2015

33. Child Outcomes Summary (COS) Process [http:/ectacenter.org/eco/pages/cos.asp]. Accessed 21 Feb 2018.

34. Davies HTO, Crombie IK, Tavakoli M. When can odds ratios mislead? BMJ. 1998;316(7136):989-91

35. Brzoska P. Using average marginal effects over odds ratios as measures of effect size in epidemiology. Ann Epidemiol. 2017;27(8):525-6.

36. Zuckerman KE, Mattox KM, Sinche BK, Blaschke GS, Bethell C. Racial, ethnic, and language disparities in early childhood developmental/behavioral evaluations: a narrative review. Clin Pediatr (Phila). 2014;53(7):619-31.

37. Tang BG, Feldman HM, Huffman LC, Kagawa KJ, Gould JB. Missed opportunities in the referral of high-risk infants to early intervention. Pediatrics. 2012;129(6):1027-34.

38. McManus B, Rapport M, Richardson Z, Lindrooth R. Therapy use for children with developmental conditions. Pediatr Phys Ther. 2017:29(3):192-8.

39. McManus B, Prosser L, Gannotti M. Unmet need for therapy services among a national sample of children with special health care needs and activity limitations. PTJ. 2016;96(2):222-31.

40. National Survey of Children's Health. Data query from the Child and Adolescent Health Measurement Initiative, Data Resource Center for Child and Adolescent Health website. In.; 2011/12.

41. McManus B, McCormick MC, Acevedo-Garcia D, Ganz M, Hauser-Cram P. The effect of state early intervention eligibility policy on participation among a cohort of young CSHCN. Pediatrics. 2009:124(Suppl 4):S368-74.

\section{Publisher's Note}

Springer Nature remains neutral with regard to jurisdictional claims in published maps and institutional affiliations. 